\title{
Hybrid energy storage system control analogous to power quality enhancement operation of interlinking converters
}

\author{
Salman Hajiaghasi ${ }^{1}$, Ahmad Salemnia ${ }^{2}$, Mohsen Hamzeh ${ }^{3}$ \\ ${ }^{1,2}$ Faculty of Electrical Engineering, Shahid Beheshti University, Iran \\ ${ }^{3}$ Faculty of Electrical Engineering, Univercity of Tehran, Iran
}

\begin{tabular}{|c|c|}
\hline Article Info & ABSTRACT \\
\hline Article history: & Increasing nonlinear loads and power electronic converters lead to various \\
\hline Received Jun 12, 2019 & $\begin{array}{l}\text { power quality issues in microgrids (MGs). The interlinking converters (ILCs) } \\
\text { can participate in these systems to harmonic control and power quality }\end{array}$ \\
\hline Revised Jul 22, 2020 & enhancement. However, ILC participation deteriorates the dc link voltage, \\
\hline Accepted Aug 30, 2020 & $\begin{array}{l}\text { system stability, and storage lifetime due to oscillatory current phenomena. } \\
\text { To address these problems, a new control strategy for a hybrid energy storage }\end{array}$ \\
\hline Keywords: & $\begin{array}{l}\text { system (HESS) is proposed to eliminate the adverse effects of the harmonic } \\
\text { control operation of ILC. Specifically, battery and super-capacitor (SC) are }\end{array}$ \\
\hline Hybrid energy storage & used as HESSs that provide low and high power frequency load, respectively. \\
\hline Interlinking converter & $\begin{array}{l}\text { The proposed strategy tries to compensate the current oscillation imposed by } \\
\text { ILC with fuzzy control of HESS. In this method, a proportional-resonant }\end{array}$ \\
\hline Microgrid & (PR) controller integrated with harmonic compensator (HC) is employed to \\
\hline Nonlinear load & $\begin{array}{l}\text { control the ILC for power quality enhancement and oscillatory current } \\
\text { elimination. The main advantages of the proposed strategy are to reduce DGs } \\
\text { power fluctuations, precise DC bus voltage regulation for generation and load } \\
\text { disturbances, improved grid power quality under nonlinear load and } \\
\text { transition conditions. The performance of the proposed method for isolated } \\
\text { and grid-connected modes is verified using simulation studies in the } \\
\text { MATLAB software environment. }\end{array}$ \\
\hline
\end{tabular}

This is an open access article under the CC BY-SA license.

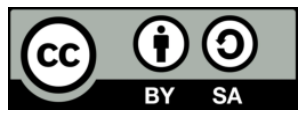

\section{Corresponding Author:}

Ahmad Salemnia

Faculty of Electrical Engineering

Shahid Beheshti University

Evin, Shahriyari Squarer, Tehran, Iran

Email: A_Salemnia@sbu.ac.ir

\section{INTRODUCTION}

Nowadays, renewable energy sources (RES) such as wind turbines, photovoltaic (PV) arrays, fuel cells, dc loads and energy storage components are increasingly being connected to the distribution grids $[1,2]$. ILC is an efficient solution to connect the dc MGs to the upstream ac grid, introducing full controllability for power exchange, power quality, and reliability enhancement, voltage regulation and etc. Respect to the increased nonlinear loads such as diode rectifiers and adjustable-speed ac motor drives in distribution networks, the MG voltage at the point of common coupling (PCC) can be distorted. In case of large nonlinear loads, harmonic content should be decreased using passive or active power filters which are an expensive solution, so ILCs can be effectively used to suppress harmonic currents imposed by nonlinear loads. The ILCs can contribute to voltage stability improvement [3,4], voltage unbalance compensation [5, 6], flicker mitigation [7], harmonic compensation [8-10] and reactive power compensation [11] in MGs and distribution networks. As the number of nonlinear loads is growing rapidly in distribution systems, ILC harmonics compensation plays an interesting and important role. Harmonic compensation can be 
accomplished using the local or central controller. Many researchers utilized ILC to compensate harmonic loads in grid-connected and islanded MGs.

A comprehensive review of harmonic compensation methods using ILCs is presented in [12, 13]. Some references have used inverters for harmonics compensation in hybrid MGs [14]. In order to improve the power quality of the distribution network, two virtual impedance-based harmonics control strategy is proposed in [14] which feedback controller and delay are employed. These control strategies do not rely on closed-loop feedback control and therefore, they are appropriate for ILCs with low switching frequency. In order to compensate harmonics/inter-harmonics, a nonlinear current control method based on high-order sliding and back stepping control is proposed in [15]. The control method robustly regulates the ILC output currents and delivers pure sinusoidal currents to the grid under nonlinear and unbalanced loads. To improve grid current quality under nonlinear local loads, a load current feedforward loop for ILC control is proposed in [16]. A unified load current feedforward control method that enables both grid-tied and islanded operations of ILC in DGs, is presented in [17]. When ILCs are used for harmonic or unbalance loads compensation, second harmonic currents (SCHs) called oscillatory current components (OCC), are created [18]. The oscillatory currents are injected to the dc bus of MG or DG due to the harmonic loads, unbalanced threephase and single-phase loads. The OCC creates several issues especially when power sources such as PV, FC, and energy storage devices are connected to the dc grid. Some of the problems are described as follows: i) Oscillatory current variations lead to battery lifetime reduction [19]; ii) Oscillation currents reduce the efficiency of the power converters; iii) The oscillatory current components have negative effects on FC performance including reduce FC lifespan and fuel consumption [20]; iv) DC link voltage distortion and instability; v) Oscillatory currents may cause a significant impact on the output power of PV systems [21]; vi) These problems drastically deteriorate system reliability, stability, and capability, particularly if the DG units cannot meet the upper limit to provide the total oscillatory current demand.

Energy storage devices can be used as active filters for harmonic compensation in MGs [22, 23]. However, conventional storages such as batteries are limited in cases of lifetime and power density [24]. To solve the mentioned problems, HESSs are employed in this paper. In this paper, the effect of nonlinear loads on the dc link in both operation modes are discussed. The proposed control strategy includes a resonant PR controller dedicated to harmonic elimination which associated with a developed fuzzy controller for OCC reduction. The fuzzy rule of the controller is obtained through simulation studies conducted in both modes. The proposed controllers are independent and can be separately tuned. The main contributions of this paper are: i) This paper proposed harmonic compensation by HESS that improves grid power quality and prevents harmonics injection to the grid; ii) A new control method for HESS control in dc side of ILC; iii) Better performance improvement under transient and load change conditions; iv) The power management performance improvement to increase the storage lifetime especially the batteries.

\section{CASE STUDY SYSTEM DESCRIPTION}

Harmonic control of ILC causes several problems which can be compensated by HESSs. To address the adverse effect of the ILC operation and capability of the proposed method, the under study system is shown in Figure 1.

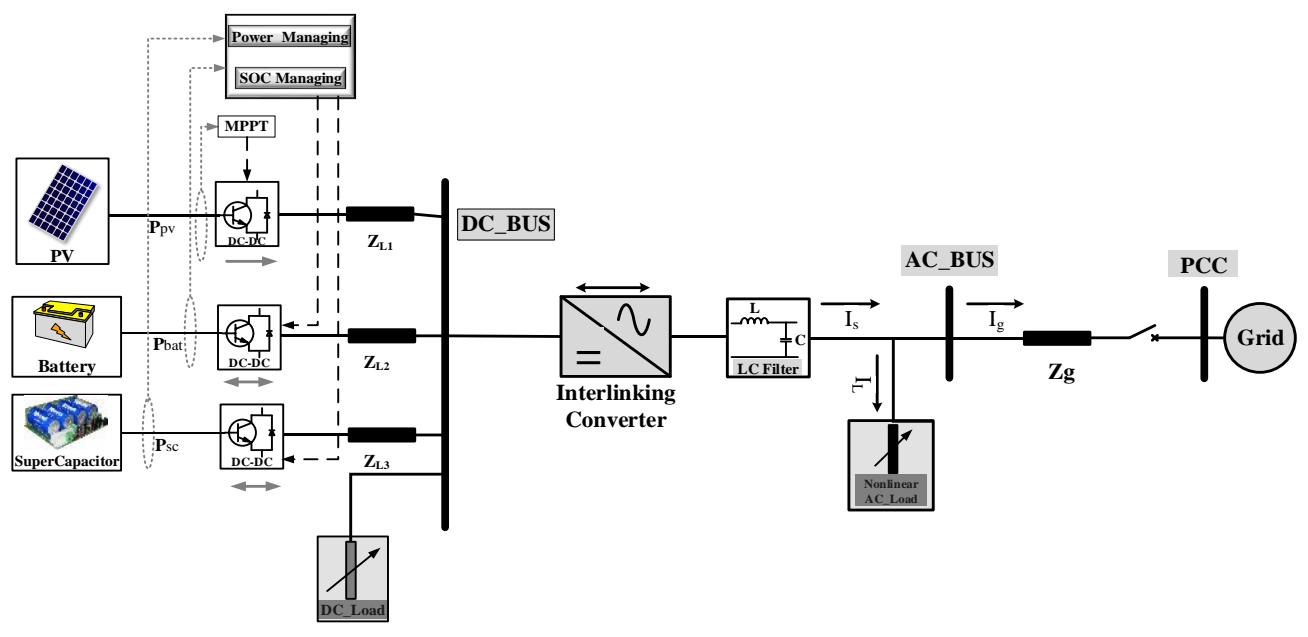

Figure 1. Hybrid power system under study 
The hybrid system consists of a PV generation system, a battery-SC HESS, dc load, an ILC that transfers power from dc bus to ac bus or vice versa, LC filter, upstream power grid, and the ac load. A boost converter is used for PV system connection to dc bus. The HESS supplies both transient and steady-state power fluctuation. The SC supply fluctuating/transient as well as oscillatory power changes. While battery supplies constant power changes due to its high energy density.

\section{PROPOSED CONTROL STRATEGY}

Figure 2 shows the overall control block diagram of ILC in islanded and grid-connected mode. The proportional resonance (PR) controller plus harmonic compensator (HC) are used to control the current and voltage of the ILC that provide the harmonic components. The transfer function of the PR and the HC controllers can be represented as (1) and (2) respectively.

$$
\begin{aligned}
& \mathrm{PR}=\mathrm{k}_{\mathrm{P}}+\frac{\mathrm{k}_{\mathrm{R}} \mathrm{s}}{\mathrm{s}^{2}+\zeta \mathrm{s}+\omega^{2}} \\
& \mathrm{HC}=\sum_{\mathrm{n}=3,5,7,11, \ldots .} \frac{\mathrm{k}_{\mathrm{Rn}} \mathrm{s}}{\mathrm{s}^{2}+\zeta \mathrm{s}+(\mathrm{n} \omega)^{2}}
\end{aligned}
$$

where $\omega$ denotes the fundamental angular frequency, $k_{P}$ is the proportional coefficient, $k_{R}$ is the resonant coefficient, $n$ is the harmonic number and $\zeta$ is used to limit the controller gain at system nominal frequency. $\mathrm{HC}$ is used to compensate the odd harmonic components. To eliminate the negative effect of grid voltage disturbances on the current controller loop in the grid-connected mode, grid voltage feed-forward is used which is shown in Figure 2. The PR controllers are used for the voltage and current control loops and space vector modulation (SVM) switching is used to generate three-phase voltage reference.

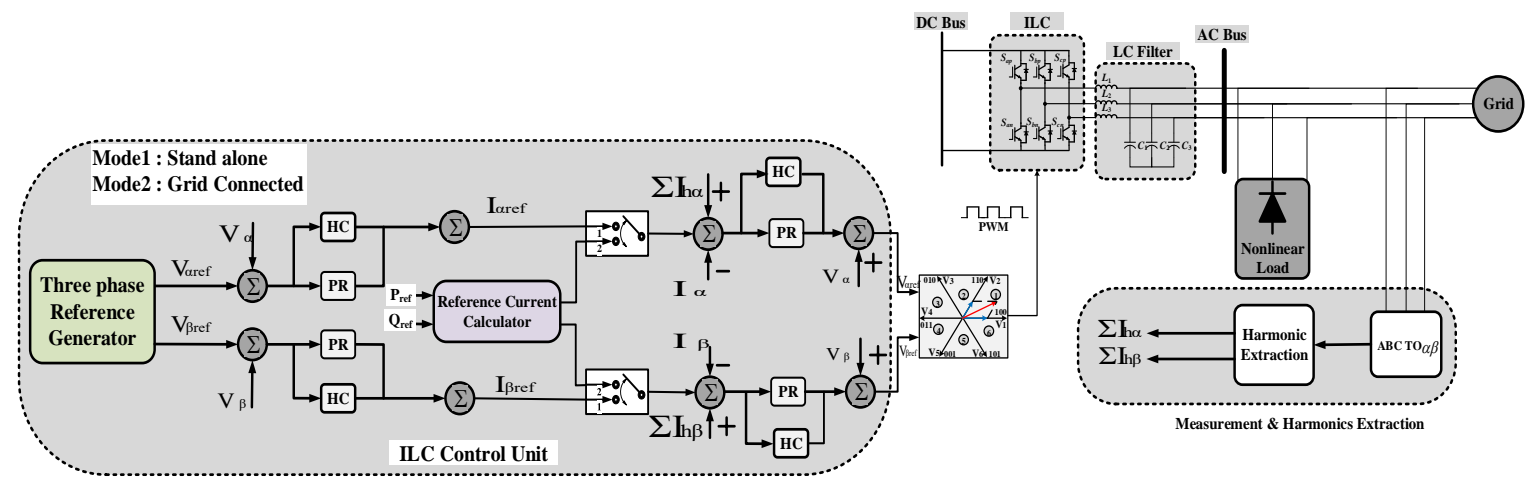

Figure 2. ILC control strategy in different operations modes

During the harmonic control of ILC, some negative effect appear on the dc side. Oscillatory dc current elimination and accurate voltage regulation under nonlinear load and transient conditions is the main target of the proposed control strategy. The block diagram of the proposed control scheme of HESS is shown in Figure 3. Ignoring the losses, the following relationships can be written as

$$
\begin{aligned}
& P_{L}(t)-P_{G}(t)=P_{b a t}(t)+P_{s c}(t)=P_{a v}(t)+P_{\text {tran }}(t) \text { for islanded mode } \\
& P_{L}(t)+P_{\text {Ref }}(t)-P_{G}(t)=P_{b a t}(t)+P_{s c}(t)=P_{a v}(t)+P_{\text {tran }}(t) \text { for grid connected mode }
\end{aligned}
$$

where $P_{G}(t)$ is the DGs output power, $P_{b a t}(t)$ is the power supplied by the battery, $P_{L}(t)$ is the loads power, $P_{a v}(t)$ is HESS average power, $P_{t r a n}(t)$ is the HESS transient power, $P_{s c}(t)$ is the power supplied by SC, and $P_{R e f}$ is the reference of injected power to the grid. Separate reference currents for battery and SC are produced using a low pass filter and they are compared to their measured values using two PI controllers. PI controllers 
design is discussed in the next subsection. The HESS charging and discharging pattern is based on the difference between the $P_{L}$ and $P_{G}$, that is given by

$$
\text { state }\left\{\begin{array}{l}
1 \text { if } \quad \mathrm{P}_{\mathrm{HESS}}>0 \text { (Disch arging) } \\
0 \quad \text { if } \quad \mathrm{P}_{\mathrm{HESS}} \leq 0(\text { Ch arg ing })
\end{array}\right.
$$

where $\mathrm{P}_{\mathrm{HESS}}$ is hybrid storages power and SoC is the state of charge and SoC limitations of HESS are also considered. The SoC block monitors the SoC of the storages by given flag signals flagSoC+ and flagSoC- to illustrate whether the SoC has reached the minimum and maximum value respectively. The SoC flag values can be defined by

$$
\begin{aligned}
& \text { flag }_{\text {soc }+}=\left\{\begin{array}{lll}
1 & \text { if } & \mathrm{SOC} \geq \mathrm{SOC}_{\max } \\
0 & \text { if } & \mathrm{SOC}<\mathrm{SOC}_{\max }
\end{array}\right. \\
& \text { flag }_{\text {soc- }}=\left\{\begin{array}{lll}
1 & \text { if } & \mathrm{SOC} \leq \mathrm{SOC}_{\min } \\
0 & \text { if } & \mathrm{SOC}>\mathrm{SOC}_{\min }
\end{array}\right.
\end{aligned}
$$

The SoC control system is constructed using logic gates as shown in Figure 3. The SoC management block is combined with switching pulses through logic AND. Therefore, HESS charging and discharging limits are considered to prevent the destruction of storage devices under deep discharging or overcharging.

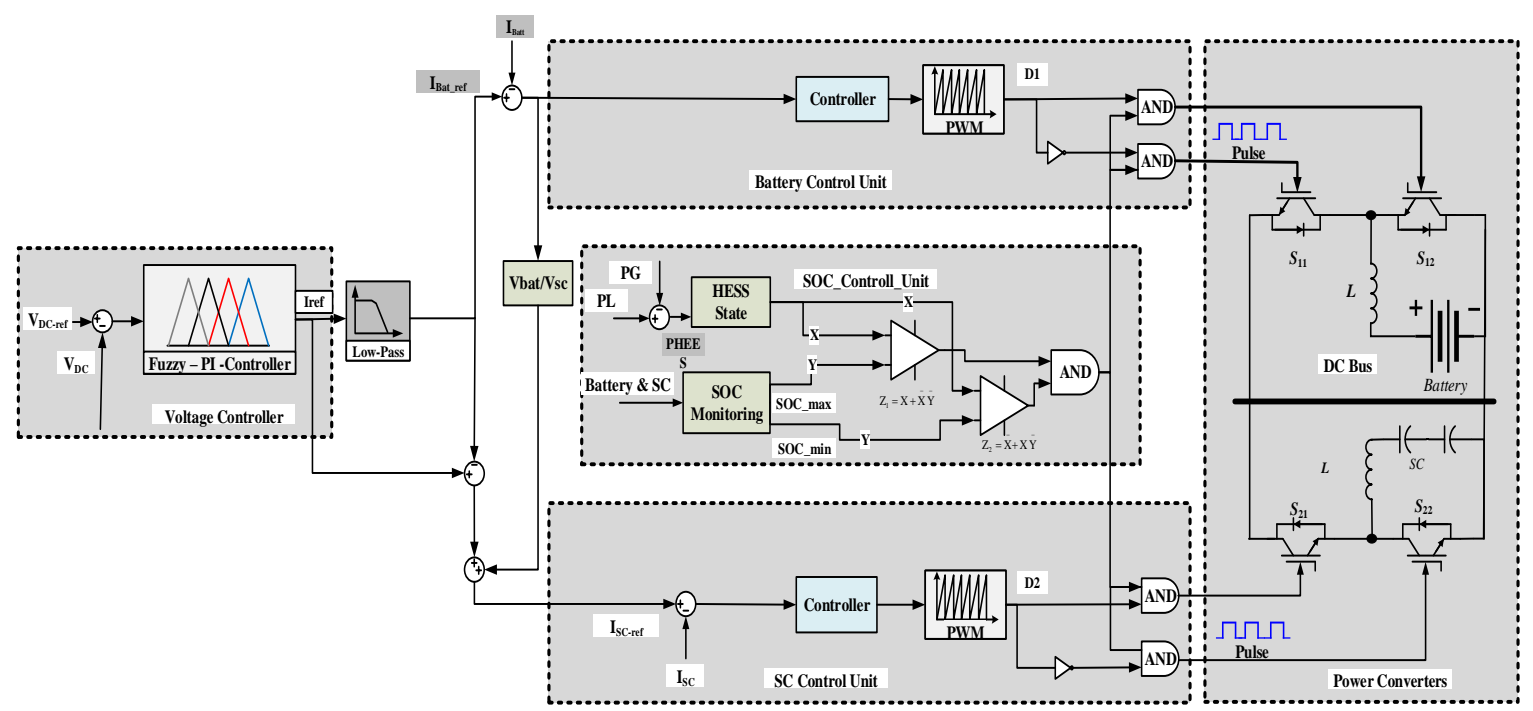

Figure 3. Proposed strategy for hybrid storages power converters control

Two PI controller is used to regulate the output power of battery and SC considering SoC constraints. voltage and current control loops are shown in Figure 4, where Gbat is the transfer function of the battery converter expressed by (8), Gcbat is transfer function of battery current controller, Gcsc is transfer function of SC current controller, Gsc is transfer function of SC converter, $G v$ is transfer function of inductor current to the output voltage. The battery current control loop transfer function can be defined as (9).

$$
\begin{aligned}
& \mathrm{G}_{\mathrm{C}_{-} \text {bat }}=\mathrm{k}_{\mathrm{P}}+\frac{\mathrm{k}_{\mathrm{i}}}{\mathrm{s}} \\
& G_{B a t}(s)=\frac{\hat{i_{b}}(s)}{\hat{d}(s)}=\frac{\left(C V_{d c}\right) s+2\left(1-D_{B a t}\right) i_{L}}{L C s^{2}+\frac{L}{R} s+\left(1-D_{B a t}\right)^{2}}
\end{aligned}
$$


where $k_{i}$ and $k_{p}$ are the integrators and the proportional gain of PI controller, $L$ and $C$ indicate the converter inductance and the dc-link capacitor respectively. $R$ represents the load resistance, $V_{d c}$ is dc-link voltage, $D_{B a t}$ is duty ratio, $i_{b}(s)$ is battery current small perturbations and $d(s)$ is small perturbations in switching duty ratio. The battery current control loop performance should be slower than the SC current control loop, therefore battery and SC controller bandwidth are considered to $1 / 10$ and $1 / 6$ switching frequency respectively. Figures 5(a) and 5(b) show Bode plots of the compensation process.

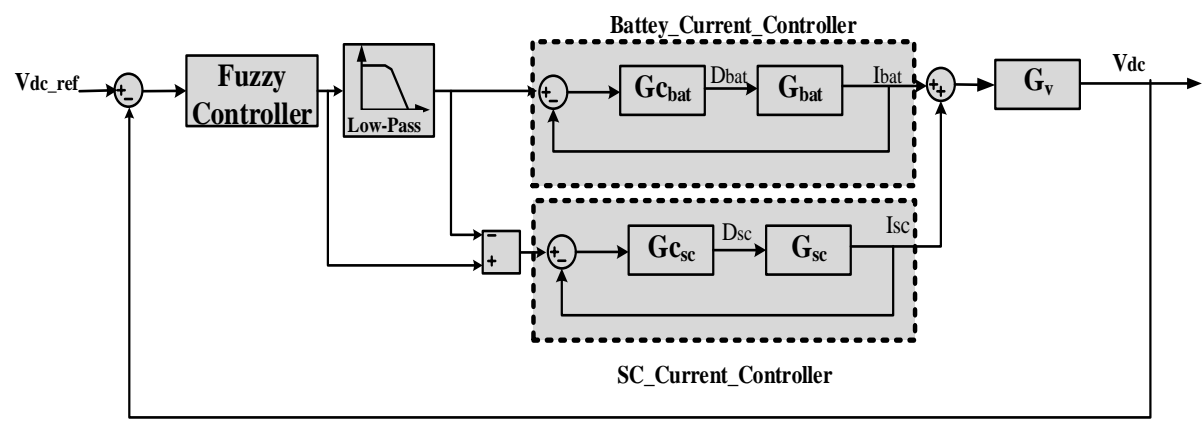

Figure 4. Transfer function block of the battery and SC

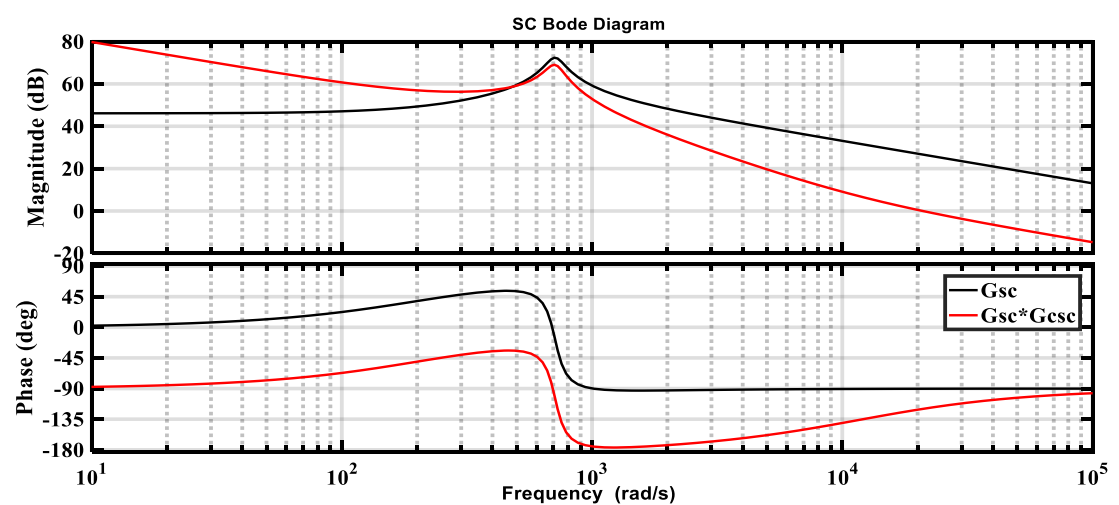

(a)

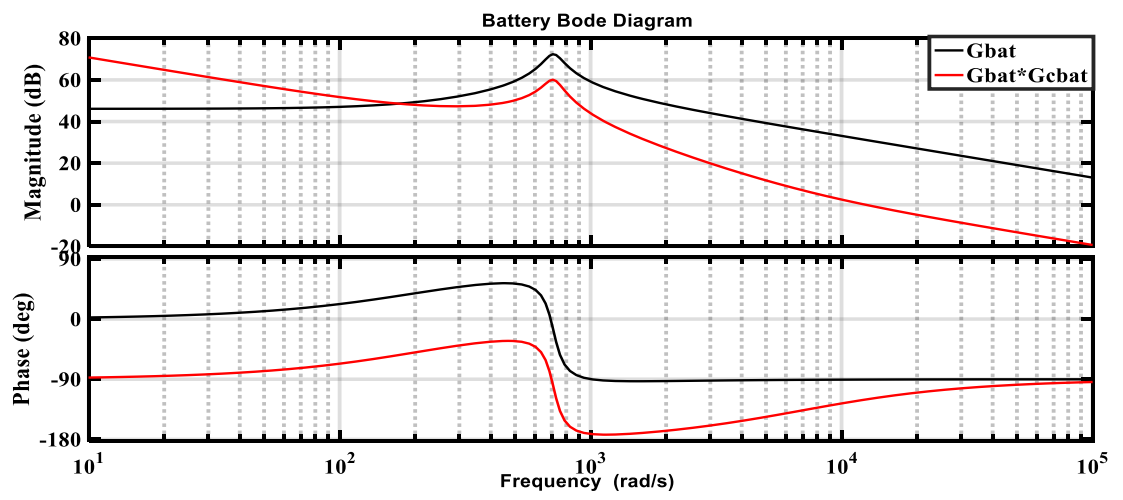

(b)

Figure 5. Bode plots of battery and SC current controllers

The PI-fuzzy controller is used in the dc-link voltage control loop to tackle the side effects of the HC operation of ILC $[25,26]$. The error and differential error of dc-link voltage is used as fuzzy controller inputs and HESSs reference currents are generated from the fuzzy controller output. Five membership functions for inputs and the output of fuzzy controller are defined. The fuzzy supervisor rules are obtained from analyzing system behavior which is shown in Table 1. 


\begin{tabular}{cccccc}
\multicolumn{7}{c}{ Table 1. Fuzzy controller rules } \\
\hline $\mathrm{NB}$ & $\mathrm{NB}$ & $\mathrm{NB}$ & $\mathrm{NB}$ & $\mathrm{NS}$ & $\mathrm{Z}$ \\
$\mathrm{NS}$ & $\mathrm{NB}$ & $\mathrm{NB}$ & $\mathrm{NS}$ & $\mathrm{Z}$ & $\mathrm{PS}$ \\
$\mathrm{Z}$ & $\mathrm{NB}$ & $\mathrm{NS}$ & $\mathrm{Z}$ & $\mathrm{PS}$ & $\mathrm{PB}$ \\
$\mathrm{PS}$ & $\mathrm{NS}$ & $\mathrm{Z}$ & $\mathrm{PB}$ & $\mathrm{PB}$ & $\mathrm{PB}$ \\
$\mathrm{PB}$ & $\mathrm{Z}$ & $\mathrm{PS}$ & $\mathrm{PB}$ & $\mathrm{PB}$ & $\mathrm{PB}$ \\
\hline
\end{tabular}

\section{SIMULATION RESULTS AND DISCUSSION}

The performance of the proposed control strategy is simulated for the system of Figure 1 in MATLAB/Simulink environment. Table 2 presents the system parameters. Different scenarios are simulated to present the robustness and ability of the proposed method under different operating conditions. To analyzing the proposed system and control algorithm, three cases are simulated. In case1, just battery unit is used as storage. In case2, battery and SC are used as storage and PI controllers are selected for dc bus voltage and current control. In case3, battery and SC are used as storage and the fuzzy-PI controller, described in the previous section, is used as a dc bus voltage controller.

Table 2. Simulation parameters

\begin{tabular}{cccccc}
\hline Symbol & Quantity & Symbol & Quantity & Symbol & Quantity \\
\hline$V_{d c}$ & $700 \mathrm{~V}$ & switching frequency & $20 \mathrm{kHz}$ & grid line voltage & $400 \mathrm{~V}$ \\
$V_{b a t}$ & $400 \mathrm{~V}$ & PV nominal power & $10 \mathrm{~kW}$ & switching frequency & $10 \mathrm{kHz}$ \\
$V_{s c}$ & $400 \mathrm{~V}$ & battery capacity & $200 \mathrm{Ah}$ & grid frequency & $50 \mathrm{~Hz}$ \\
$L_{f}$ & $2 \mathrm{mH}$ & SC capacity & $100 \mathrm{~F}$ & $C_{f}$ & $50 \mu \mathrm{f}$ \\
\hline
\end{tabular}

\subsection{Islanded mode}

Two different scenarios of linear and nonlinear loads are considered. In the first scenario, linear ac and dc loads are connected to the hybrid power system (HPS) and for the second scenario, a nonlinear load is connected to the ac bus of HPS. In the first scenario, at the initial step, a $3 \mathrm{~kW}$ ac load is connected to the HPS. A $4 \mathrm{~kW}$ dc load at $\mathrm{t}=0.2 \mathrm{~s}$ is added to the system, and at $\mathrm{t}=0.4 \mathrm{~s}$ a $5 \mathrm{kVA}$ ac load is added to the system. The dc-link voltage is shown in Figure 6(a). Compared to the conventional system (that uses the only battery as a storage device), the proposed method has better performance under load variation and transient conditions. It can be seen that all controllers have acceptable performance but the fuzzy control method has better performance under load variation and transient conditions. Figure 6(b) shows the battery bank current in various control methods. From $t=0 \mathrm{~s}$ to $\mathrm{t}=0.4 \mathrm{~s}$, the total loads power is smaller than power generated and the battery bank is charging. The loads are increased at $t=0.4 \mathrm{~s}$, storages must supply the subtraction power of generation and load so it is getting to discharge. The battery bank current has a smooth response and small variation that improves battery performance. Figure 6(c) shows the SC current. SC supplies fast and transient variation of requested current. The ILC current is shown in Figure 6(d). It is clear that the converter current is sinusoidal and with the load increases at $\mathrm{t}=0.4 \mathrm{~s}$, the ILC current is increased.

For the next scenario, the HPS feeds linear and nonlinear loads. From the beginning, a $3 \mathrm{~kW}$ linear ac load and a $7.5 \mathrm{~kW}$ nonlinear ac load are connected to the system. At $\mathrm{t}=0.2 \mathrm{~s} \mathrm{a} 4 \mathrm{~kW}$ dc load is added to the system. In $\mathrm{t}=0.3 \mathrm{~s}$, a $7.5 \mathrm{~kW}$ nonlinear load is re-added to the system, and at $\mathrm{t}=0.4 \mathrm{~s}$, a $5 \mathrm{~kW}$ ac load is added to the system. The dc-link voltage is presented in Figure 7(a). The battery current when SC- battery and just battery are used as the storage device is shown in Figure 7(b). It is clear that using the proposed method, the dc-link oscillatory current that caused by nonlinear loads is provided by the SC and the current of the battery becomes smooth. The SC current is shown in Figure 7(c), SC supplies oscillatory and transient current component.

Figure 8(a) shows the ILC current when ILC supply nonlinear load, the current flow from the ILC contains different harmonics and loses sinusoidal. According to the simulation results, it is clear that when the loads are nonlinear, the distortion current passes through the dc bus. The control system decomposes this current between storages and PV as follows: SC bank supply the transient current and high-frequency power and the battery bank and PV low power frequency, so the power quality of the hybrid power system improves. When the nonlinear load is added to the system, the ILC converter must supply different harmonic current associated with the nonlinear load and the voltage of the dc-link is distorted. The ac bus voltage is shown in Figure 8(b). Due to the large nonlinear load added to the system, the ac bus voltage becomes distorted. The dc link voltage distortion has been reduced using the proposed method. 


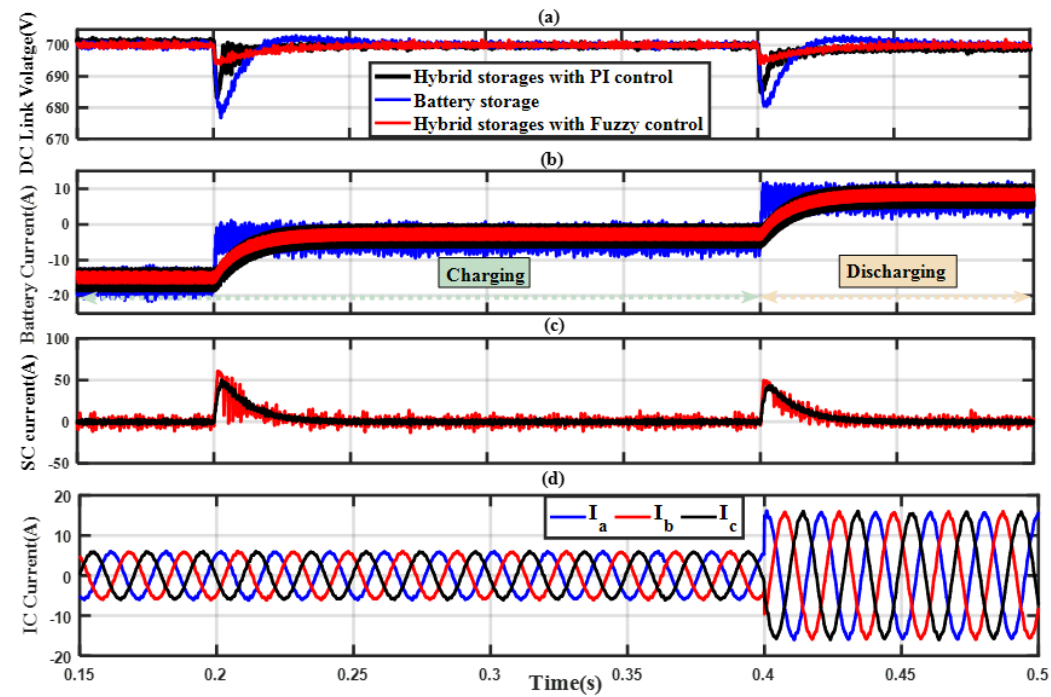

Figure 6. Simulation results for the isolated mode and linear load condition, (a) DC link voltage, (b) battery current, (c) SC current, (d) ILC current

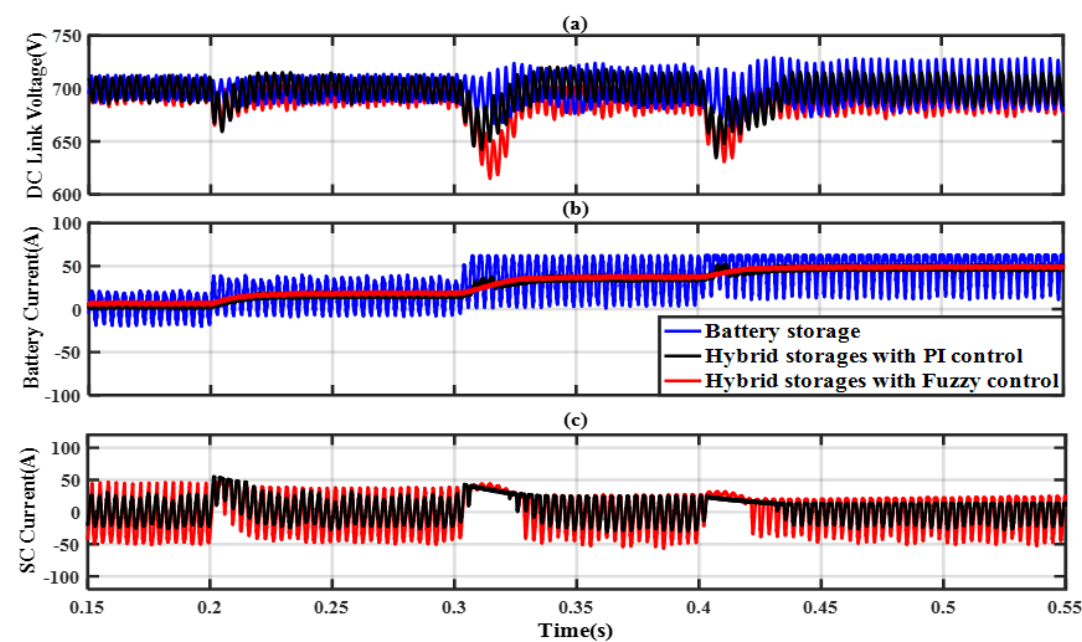

Figure 7. Isolated mode and nonlinear load condition, (a) DC link voltage, (b) battery current, (c) SC current

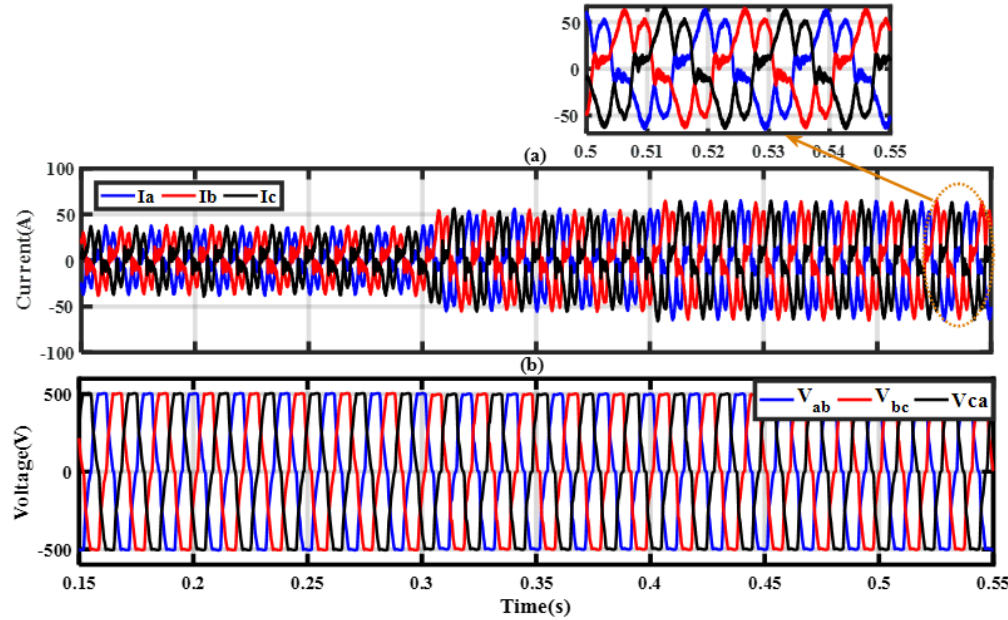

Figure 8. AC bus voltage and current under nonlinear load condition, (a) current, (b) voltage 


\subsection{Grid-connected mode}

In this section, the grid-connected mode is investigated. The reference power can be determined by the upper control system or based on different scenarios. In this scenario, HPS is connected to the grid and the nonlinear load is connected to PCC, causing to inject harmonics into the HPS. ILC must compensate harmonics so that the delivered current to and received from the grid remain sinusoidal without harmonics. The dc-link voltage is shown in Figure 9(a). It can be seen that with the proposed method, the voltage variations remained in the acceptable range. Figure $9(\mathrm{~b})$ shows the battery current. Until $\mathrm{t}=0.4 \mathrm{~s}$ the generation power is greater than set point power of ILC so the battery is charged. Reducing the amount of solar radiation at the $\mathrm{t}=0.5 \mathrm{~s}$, the battery is discharged. However, with the proposed strategy battery current is not distorted and it is perfectly smooth. The current of SC is shown in Figure 9(c). Connecting the nonlinear load to the PCC, the HPS current contains oscillatory harmonics that are supplied by the SC. PCC voltage is shown in Figure 10(a). The voltage of PCC is sinusoidal and without any distortion. The ILC current is presented in Figure 10(b). This is because most harmonic currents of the nonlinear load are absorbed by the ILC. The grid current with and without harmonic control compensation is shown in Figure 11. The current with compensation becomes more sinusoidal due to the reduction in harmonics. As can be seen, the grid current has very low harmonic current, and the nonlinear load current is supplied by the HPS.
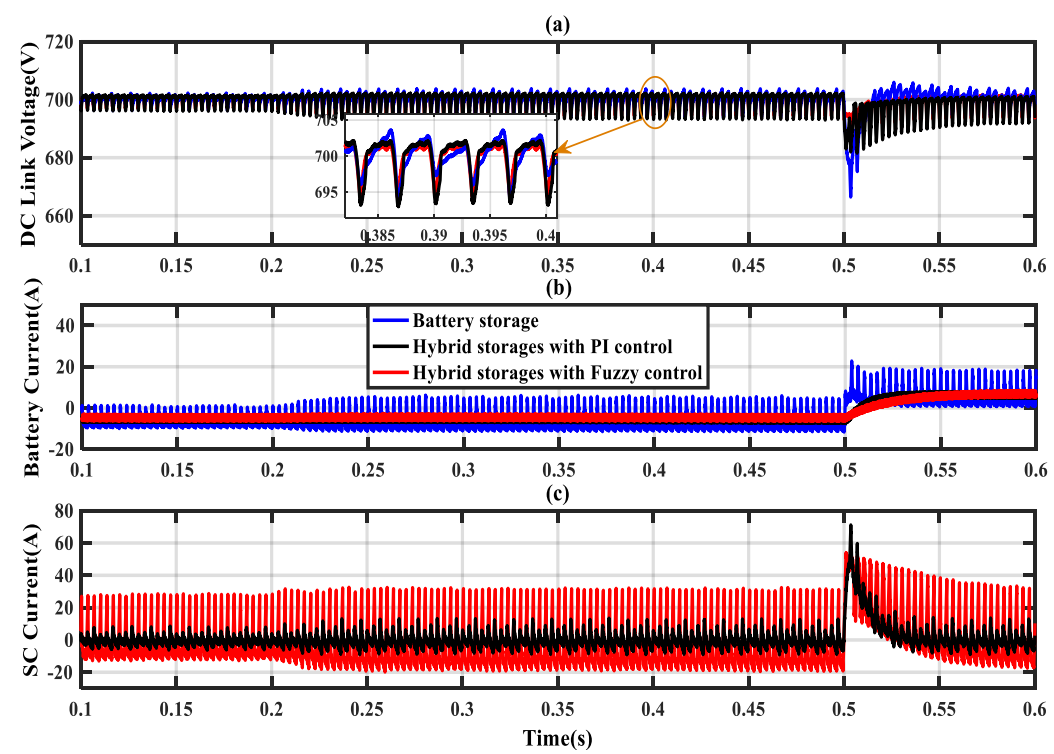

Figure 9. Grid connected mode and nonlinear load conditions,

(a) DC link voltage, (b) battery current, (c) SC current

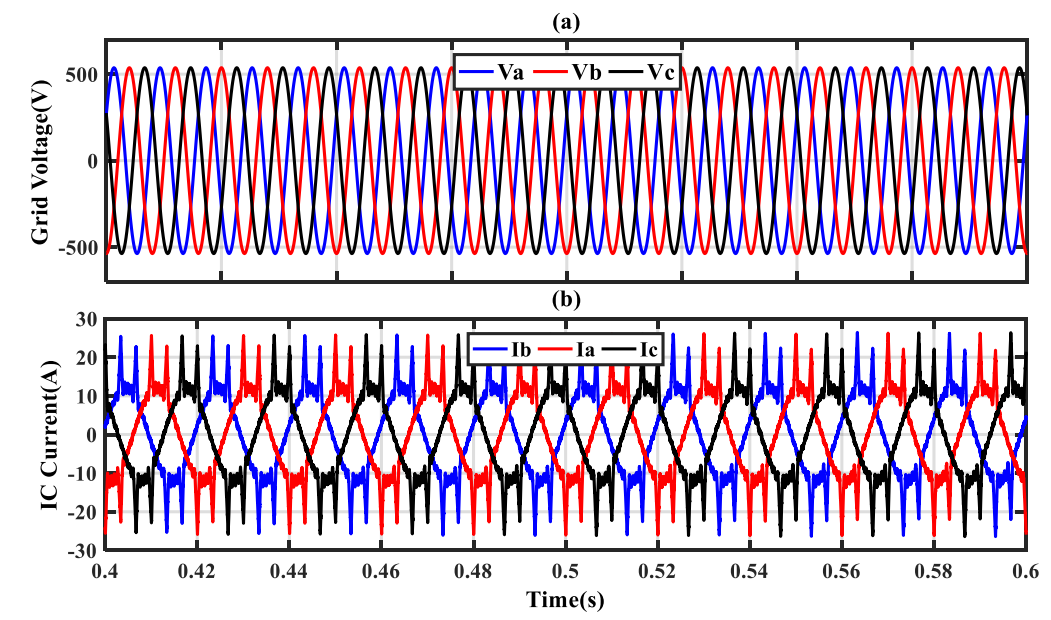

Figure 10. Grid connected mode and nonlinear load conditions, (a) PCC voltage, (b) ILC current 

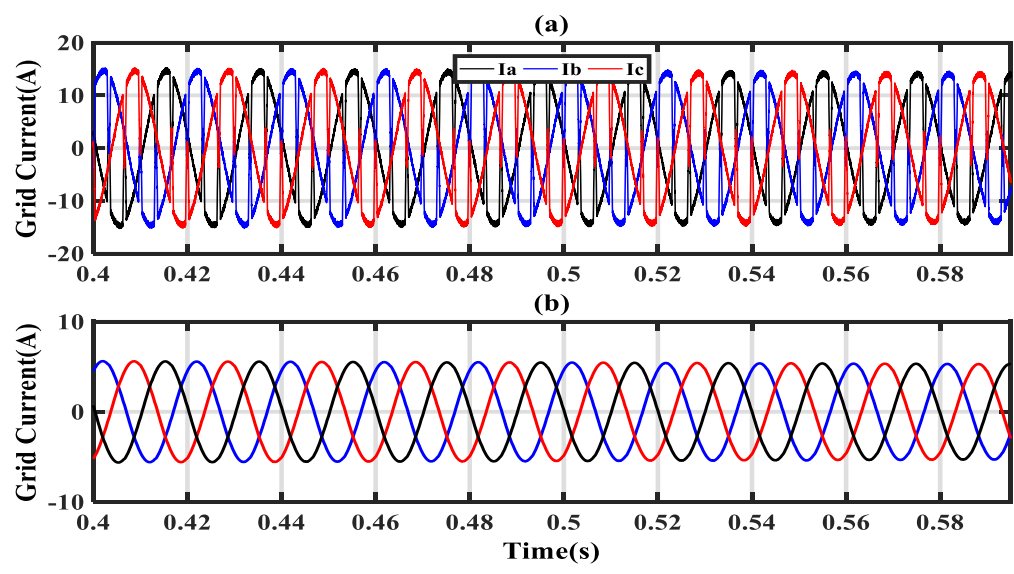

Figure 11. ILC current, (a) without harmonic compensation, (b) with harmonic compensation

\section{CONCLUSION}

In this paper, a new harmonic compensation method using HESS is proposed that can be used in MGs and DGs connected to the grid. When the nonlinear load is connected to PCC, harmonic currents distort grid power quality, the dc bus voltage and dc bus current. Using the proposed method and control strategy, the system performance improved and the DGs current stress decreases. The main advantages of the presented control strategy are harmonic compensation by HESS that improves grid power quality and prevents from injecting harmonics to the grid, better performance under transient and load change conditions and dc-link performance improvement. Moreover, the results verify that the proposed method has good performance under RES generation changes such as solar radiation change. The effectiveness of the proposed method has been verified for various operating conditions using MATLAB/Simulink software.

\section{REFERENCES}

[1] E. Banguero, et al., "Renewable microgrid operational results and economic evaluation using RETScreenTM," International Journal of Electrical and Computer Engineering (IJECE), vol. 9, no. 2, pp. 723-731, 2019.

[2] S. Hajiaghasi, et al., "A New Method For Determination of Hybrid Energy Storage Capacity in Isolated Microgrid," Energy Engineering and Management, vol. 9, no. 3, pp. 50-63, 2019.

[3] Q. Liu, et al., "Stability Analysis and Auto-Tuning of Interlinking Converters Connected to Weak Grids," IEEE Transactions on Power Electronics, vol. 34, no. 10, pp. 9435-9446, 2019.

[4] M. M. H. Ahmadi, et al., "Hybrid Energy Storage for DC Microgrid Performance Improvement under Nonlinear and Pulsed Load Conditions," in Proceedings-2018 Smart Grid Conference (SGC 2018), 2018.

[5] S. Hoseinnia, et al., "A control scheme for voltage unbalance compensation in an islanded microgrid," Electric Power Systems Research, vol. 177, p. 106016, 2019.

[6] Y. Zhang, et al., "Symmetric-component decoupled control of grid-connected inverters for voltage unbalance correction and harmonic compensation," International Journal of Electrical Power and Energy Systems, vol. 115, p. $105490,2020$.

[7] A. Arshad and M. Lehtonen, "A comprehensive voltage control strategy with voltage flicker compensation for highly PV penetrated distribution networks," Electric Power Systems Research, vol. 172, pp. 105-113, 2019.

[8] M. Hafez, et al., "Harmonic enhancement in microgrid with applications on sensitive loads," International Journal of Electrical and Computer Engineerings (IJECE), vol. 9, no. 2, pp. 826-834, 2019.

[9] D. C. Silva Júnior, et al., "Control of a multi-functional inverter in an AC microgrid Real-time simulation with control hardware in the loop," Electric Power Systems Research, vol. 172, pp. 201-212, 2019.

[10] P. Goleij, et al., "A New Hybridization Concept for Distributed Generation and Microgrids under Harmonic and Nonlinear Loads," in Proceedings-2018 Smart Grid Conference (SGC 2018), 2018.

[11] H. M. A. Antunes, et al., "A new multifunctional converter based on a series compensator applied to AC microgrids," International Journal of Electrical Power and Energy Systems, vol. 102, pp. 160-170, 2018.

[12] Y. W. Li and J. He, "Distribution System Harmonic Compensation Methods: An Overview of DG-Interfacing Inverters," IEEE Industrial Electronics Magazine, vol. 8, no. 4, pp. 18-31, 2014.

[13] A. Ordono, et al., "Interlinking converters and their contribution to primary regulation: a review," International Journal of Electrical Power and Energy Systems, vol. 111, pp. 44-57, 2019.

[14] H. Tian, et al., "Hybrid AC/DC System Harmonics Control Through Grid Interfacing Converters With Low Switching Frequency," IEEE Transaction on Industrial Electronics, vol. 65, no. 3, pp. 2256-2267, 2018.

[15] N. M. Dehkordi, et al., "A Robust Backstepping High-Order Sliding Mode Control Strategy for Grid-Connected DG Units With Harmonic/Interharmonic Current Compensation Capability," IEEE Transactions on Sustainable Energy, vol. 8, no. 2, pp. 561-572, 2017. 
[16] Q. N. Trinh and H. H. Lee, “An Enhanced Grid Current Compensator for Grid-Connected Distributed Generation Under Nonlinear Loads and Grid Voltage Distortions," IEEE Transactions on Industrial Electronics, vol. 61, no. 12 , pp. 6528-6537, 2014.

[17] Z. Liu, et al., "A Unified Control Strategy for Three-Phase Inverter in Distributed Generation," IEEE Transaction on Power Electronics, vol. 29, no. 3, pp. 1176-1191, 2014

[18] M. Hamzeh, et al., "Modeling and Design of an Oscillatory Current-Sharing Control Strategy in DC Microgrids," IEEE Transaction on Industrial Electronics, vol. 62, no. 11, pp. 6647-6657, 2015.

[19] T. Weitzel, et al., "Operating a storage-augmented hybrid microgrid considering battery aging costs," Journal of Cleaner Production, vol. 188, pp. 638-654, 2018.

[20] M. İnci and Ö. Türksoy, "Review of fuel cells to grid interface: Configurations, technical challenges and trends," Journal of Cleaner Production, vol. 213, pp. 1353-1370, 2019.

[21] A. Vinayagam, et al., "Harmonics assessment and mitigation in a photovoltaic integrated network," Sustainable Energy, Grids Networks, vol. 20, p. 100264, 2019.

[22] A. Amirullah, et al., "Matlab/simulink simulation of unified power quality conditioner-battery energy storage system supplied by PV-wind hybrid using fuzzy logic controller," International Journal of Electrical and Computer Engineering, vol. 9, no. 3, pp. 1479-1495, 2019.

[23] K. Rabyi and H. Mahmoudi, "Energy storage of DFIG based wind farm using D-STATCOM," International Journal of Electrical and Computer Engineering (IJECE), vol. 9, no. 2, pp. 761-770, 2019.

[24] S. Hajiaghasi, et al., "Hybrid energy storage system for microgrids applications: A review," Journal of Energy Storage, vol. 21, pp. 543-570, 2019.

[25] S. Hajiaghasi, et al., "Hybrid energy storage performance improvement in microgrid application," in 20189 th Annual Power Electronics, Drives Systems and Technologies Conference (PEDSTC), pp. 392-397, 2018.

[26] S. Hajiaghasi, et al., "Hybrid Energy Storage For Microgrid Performance Improvement Under unbalanced load Conditions," Iran Energy Association, vol. 2, no. 1, pp. 32-38, 2018.

\section{BIOGRAPHIES OF AUTHORS}

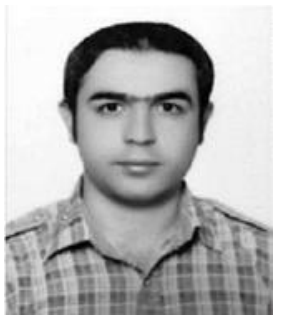

Salman Hajiaghasi is currently $\mathrm{PhD}$ student of Electrical Engineering at Shahid BeheshtiUniversity, Tehran, Iran. His research interests include power electronic and microgrids.

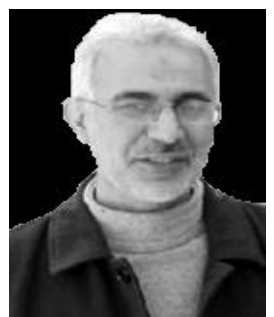

Ahmad Salemnia received Ph.D. degree from Polytechnic Institute of Lorraine (INPL), France, in 1996, in Electrical Engineering. He joined Shahid Beheshti University, Tehran, Iran, in 1990, where he is currently an Assistant Professor.

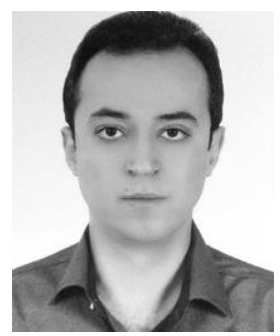

Mohsen Hamzeh (S'09-M'13) received the Ph.D. degree from Sharif University of Technology, Tehran, Iran, in 2012, in electrical engineering. He is currently an Assistant Professor in university of tehran. His research interests include renewable energies and microgrid. 